\title{
Growth and Characterization of Urea Adduct with m-Nitrobenzoic Acid, m-Nitroaniline, and p-Xylene Mixtures
}

\author{
P. Jagdish ${ }^{{ }^{*}}$, N.P. Rajesh ${ }^{2}$, S. Natarajan ${ }^{3}$ \\ ${ }^{1}$ Department of Physics, Sona College of Technology, Salem - 636 005, India \\ ${ }^{2}$ Centre for Crystal Growth, SSN College of Engineering, Kalavakkam - 636 110, India. \\ ${ }^{3}$ School of Physics, Madurai Kamaraj University, Madurai - 625 021, India. \\ *Corresponding author: jaggphy1975@yahoo.co.in, jaggphy2002@yahoo.co.in
}

\begin{abstract}
The urea adduct with the guests of m-nitrobenzoic acid, m-nitroaniline and p-xylene mixtures by adductive crystallization was successfully grown by slow evaporation method. The single crystals obtained were non-hygroscopic and good in size. The crystal structure of the grown crystal has been determined, and it belongs to the monoclinic system with centrosymmertic space group $\mathrm{P} 2{ }_{1}$ c. Fourier transform infrared spectroscopic studies were performed for the identification of guest components in the compound. The optical absorption spectrum has been recorded in the range 200-1100 $\mathrm{nm}$. The mechanical behavior of the specimen was studied.
\end{abstract}

Key words: X-ray diffraction, Growth from solutions, Organic adduct.

\section{INTRODUCTION}

The development of new optical organic materials is of great interest due to their higher orders of optical transparencies than the conventional inorganic materials. Due to promising optical properties, the organic materials can be utilized in optical device fabrication which can replace the electronic switching circuits [1]. So it is required to grow highly perfect single crystals of organic optical materials for optical devices fabrication with unique properties such as good transparency, large birefringence and frequency mixing in the large range of spectrum including the ultraviolet spectrum [2-6]. In this work, a new organic adduct has been formed with urea, mnitrobenzoic acid, m-nitroaniline and p-xylene mixtures and was grown as a single crystal. In the present investigation, we report the synthesis, crystal growth, single-crystal X-ray diffraction 
(XRD) studies, Fourier transform infrared (FT-IR) spectroscopy, optical transmission (UV-visNIR), Vicker's micro hardness test of the new organic adduct.

\section{EXPERIMENTAL}

\subsection{Synthesis}

The organic adduct was synthesized by the combination of urea (Merck, 99.5\% pure), mnitrobenzoic acid (Merck, 99.5\% pure), m-nitroaniline (Merck, 99.5\% pure) and p-xylene (AR grade) along with methanol (AR grade) as solvent. Homogeneous solutions were prepared by dissolving $17.48 \mathrm{~g}, 13.812 \mathrm{~g}$ and $16.7 \mathrm{~g}$ of urea, m-nitrobenzoic acid and m-nitroaniline, respectively, in methanol of $100 \mathrm{ml}$ each. The three solutions thus formed were thoroughly mixed by constant stirring along with p-xylene $(100 \mathrm{ml})$ in the ratio $1: 1: 1: 1$ and heated to a temperature of $40^{\circ} \mathrm{C}$. The solution was then filtered out and kept undisturbed at a temperature of $40^{\circ} \mathrm{C}$ in a closed beaker with provision for controlled evaporation. After a period of one week, crystalline material of urea adducts with organic mixture was separated out and dried using a vacuum oven. The purity of the synthesized salt was further improved by successive recrystallization of the compound in methanol.

\subsection{Crystal Growth}

Single crystals of urea adduct with m-nitrobenzoic acid, m-nitroaniline and p-xylene mixture were grown by solvent evaporation technique at room temperature. Appropriate selection of solvent for the growth of the material is very important in crystal growth process. Methanol was found to be the suitable solvent for preparing the growth solutions. Recrystallized compound was dissolved in methanol to prepare a saturated solution. The solution was filtered and kept undisturbed in a dust free environment at room temperature. The rate of evaporation of the solvent was controlled critically for a period of thirty days. Finally the single crystals of urea adduct with m-nitrobenzoic acid, m-nitroaniline and p-xylene mixture were harvested. Figure 1 shows the photograph of the harvested single crystal exhibiting birefringence property. 


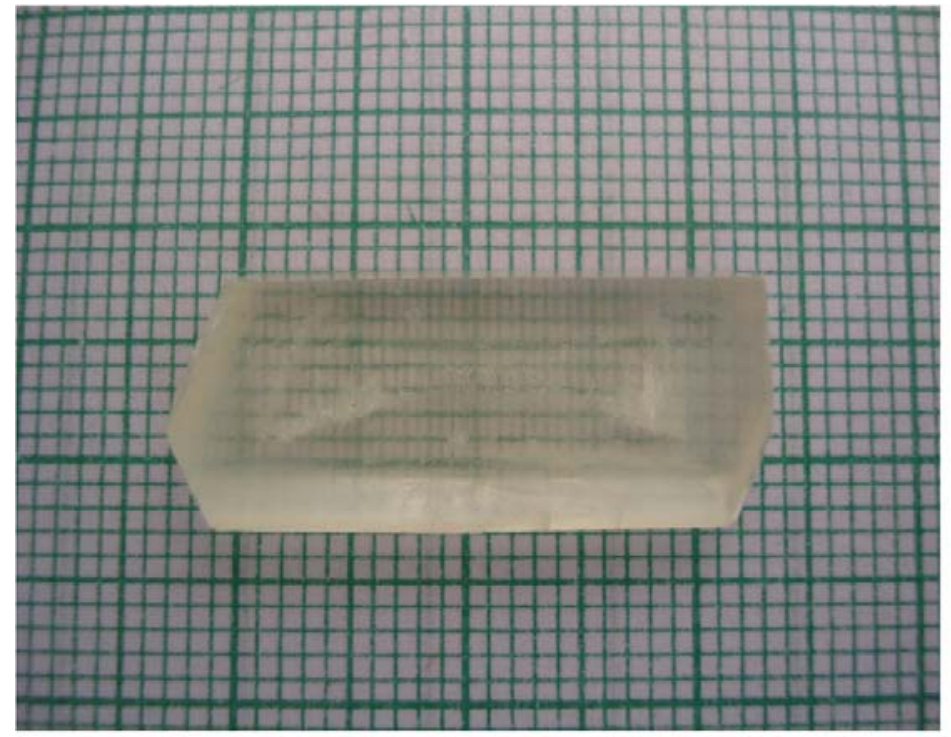

Figure 1. Photograph of urea adduct with m-nitrobenzoic acid-m-nitroaniline-p-xylene mixture single crystal $\left(\mathrm{C}_{8} \mathrm{H}_{9} \mathrm{~N}_{3} \mathrm{O}_{5}\right)$.

\section{RESULTS AND DISCUSSIONS}

\subsection{X-ray Diffraction Analysis}

To obtain the unit cell parameters and to confirm the crystallinity of grown crystals, both single crystal and powder crystal X-ray diffraction studies were carried out. Single crystal X-ray diffraction pattern was recorded using single crystal diffractometer CAD 4/MACH 3 with MoKa radiation in the wavelength $0.71073 \AA$ Á. The cell parameters were calculated by data reduction and the structure was solved. The unit cell parameters were measured at $293 \mathrm{~K}$. The unit cell dimensions were determined as $\mathrm{a}=8.093$ (5) $\AA, \mathrm{b}=12.750$ (5) $\AA, \mathrm{c}=9.502$ (5) $\AA, \alpha=90.00^{\circ}, \beta$ $=93.39(5)^{\circ}, \gamma=90.00^{\circ}$ and the cell volume of 978.8 (9) $\AA^{3}$ with a molecular weight of $227.18 \mathrm{~g}$. The crystal belongs to monoclinic crystal system with space group of $\mathrm{P} 2{ }_{1} / \mathrm{c}$. The crystal data, experimental conditions and structural refinement parameters of urea adduct with m-nitrobenzoic acid-m-nitroaniline-p-xylene mixture single crystal are presented in Table 1.

Figure 2 shows the planar molecular structure of the adduct that has been determined by single crystal XRD. The molecular packing diagram given in Figure 3 shows four molecules per unit cell. The calculated cell parameters were also searched through Cambridge Structural Database which revealed that the crystal grown is a new organic adduct. 
Table 1. Crystal data and structure refinement for urea adducts with m-nitrobenzoic acid-mnitroaniline-p-xylene mixture single crystal $\left(\mathrm{C}_{8} \mathrm{H}_{9} \mathrm{~N}_{3} \mathrm{O}_{5}\right)$.

\begin{tabular}{|c|c|}
\hline Empirical formula & $\mathrm{C}_{8} \mathrm{H}_{9} \mathrm{~N}_{3} \mathrm{O}_{5}$ \\
\hline Formula weight & 227.18 \\
\hline Temperature & $293(2) \mathrm{K}$ \\
\hline Wavelength & $0.71069 \AA$ \\
\hline Crystal system & Monoclinic \\
\hline Space group & $\mathrm{P} 22_{1} / \mathrm{c}$ \\
\hline Unit cell dimensions & 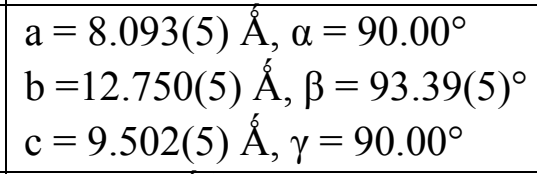 \\
\hline Volume & $978.8(9) \AA^{3}$ \\
\hline Z, Calculated density & $4,1.542 \mathrm{gm} / \mathrm{cc}$ \\
\hline Absorption coefficient & $0.130 \mathrm{~mm}^{-1}$ \\
\hline $\mathrm{F}(000)$ & 472 \\
\hline Crystal size & $0.29 \times 0.26 \times 0.21 \mathrm{~mm}^{3}$ \\
\hline Theta range for data collection & 2.52 to $24.98^{\circ}$ \\
\hline Limiting indices & $0 \leq \mathrm{h} \leq 9,-1 \leq \mathrm{k} \leq 15,-11 \leq \mathrm{l} \leq 11$ \\
\hline Reflections collected / unique & $2024 / 1717[\mathrm{R}(\mathrm{int})=0.1344]$ \\
\hline Completeness to theta & $24.98,99.6 \%$ \\
\hline Absorption correction & $\varphi$ scan \\
\hline Refinement method & Full-matrix least-squares on $\mathrm{F}^{2}$ \\
\hline Data/restraints/parameters & $1717 / 0 / 146$ \\
\hline Goodness-of-fit on $\mathrm{F}^{2}$ & 1.069 \\
\hline Final R indices $[\mathrm{I}>2 \operatorname{sigma}(\mathrm{I})]$ & $\mathrm{R} 1=0.1000, \mathrm{wR} 2=0.2676$ \\
\hline $\mathrm{R}$ indices (all data) & $\mathrm{R} 1=0.1703, \mathrm{wR} 2=0.3216$ \\
\hline Extinction coefficient & $0.016(9)$ \\
\hline Largest diff. peak and hole & 0.515 and -0.397 e. $\AA^{3}$ \\
\hline
\end{tabular}




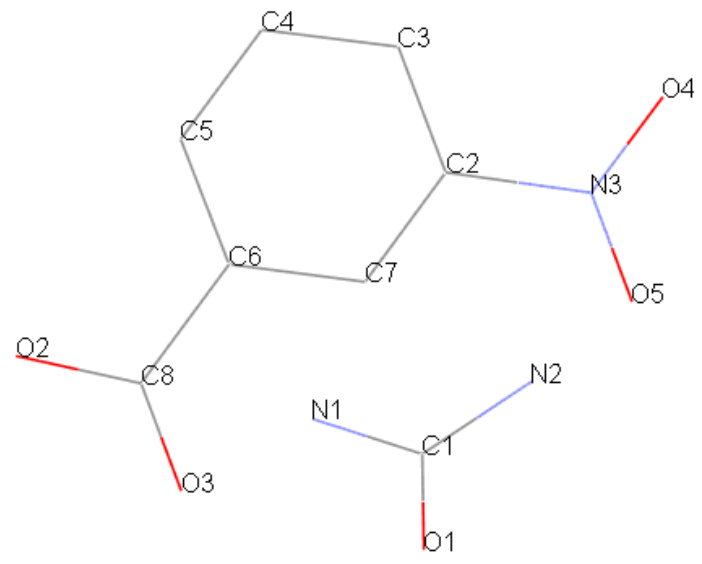

Figure 2. The molecular diagram of $\mathrm{C}_{8} \mathrm{H}_{9} \mathrm{~N}_{3} \mathrm{O}_{5}$ with numbering scheme.

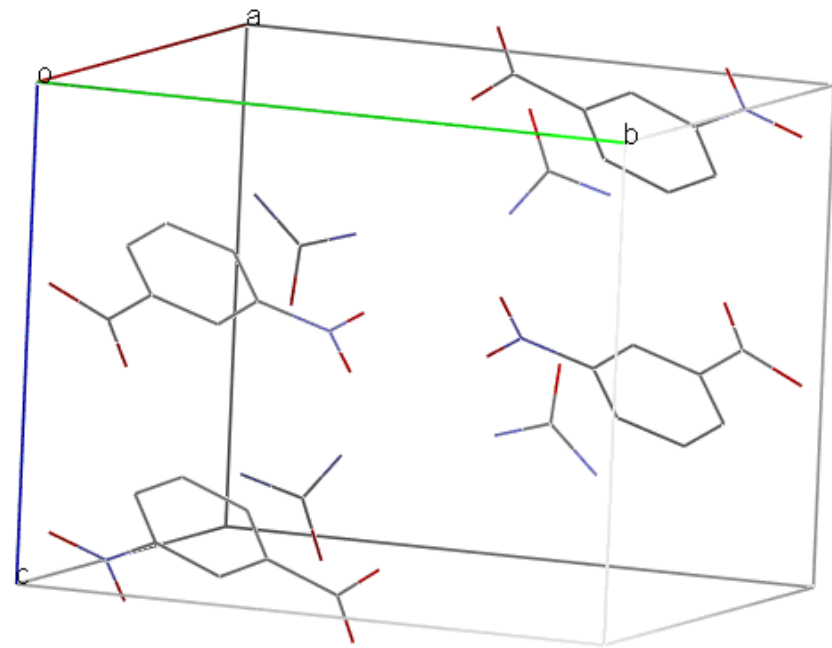

Figure 3. Molecular packing diagram of $\mathrm{C}_{8} \mathrm{H}_{9} \mathrm{~N}_{3} \mathrm{O}_{5}$ viewed down to the c-axis.

Powder X-ray diffraction study was carried out and the peaks were recorded using a microprocessor controlled X-ray diffractometer with $1.5405 \mathrm{Cu}$ wavelength as the target in reflection scan mode using scintillation counter detector. The grown crystals were finely powdered and employed for powder XRD. The sample was scanned over the range $10-70^{\circ}$ at the rate of $1 \% \mathrm{~min}$. From the X-ray diffraction data the various planes of reflections were indexed and the indexed powder X-ray diffraction pattern is given in Figure 4. 


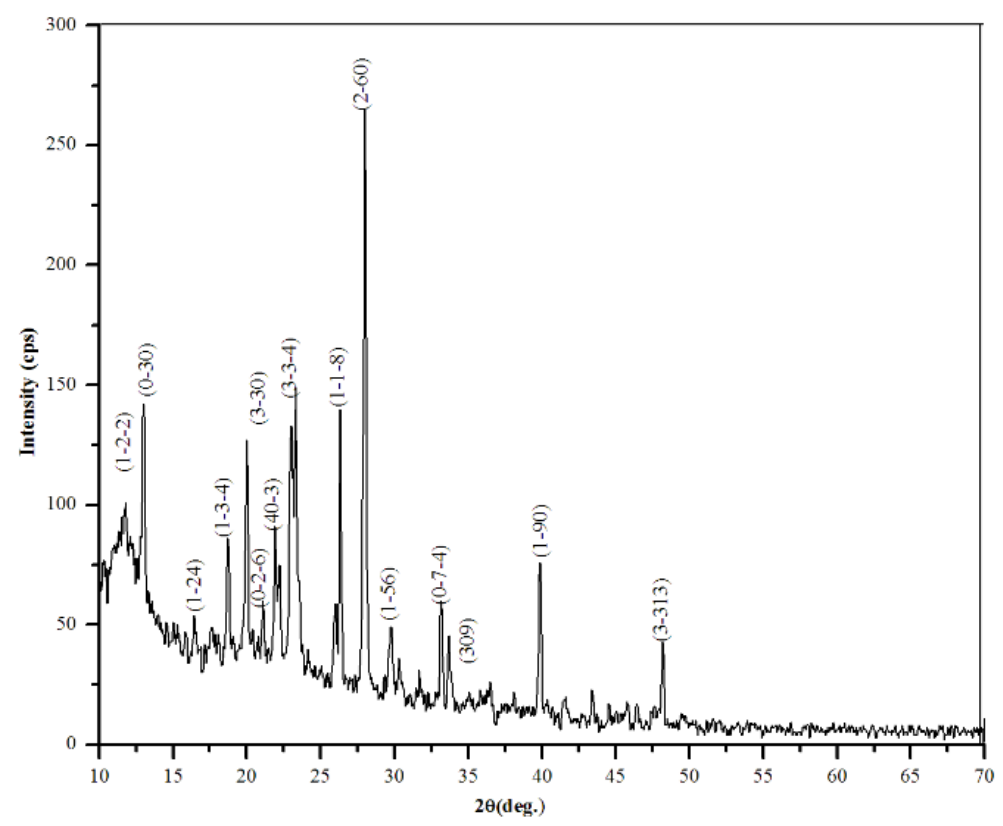

Figure 4. Powder XRD of urea adducts with m-nitrobenzoic acid-m-nitroanilinep-xylene mixture single crystal.

\subsection{FTIR Analysis}

The FTIR spectrum was recorded using a Perkin-Elmer FTIR spectrum RXI spectrometer by $\mathrm{KBr}$ pellet technique. Figure 5 shows the FTIR spectrum recorded in the range $400-4000 \mathrm{~cm}^{-1}$ at room temperature. The assignment of FTIR data of the crystal is given in Table 2, which shows the evidence of presence of different functional groups of the reactants.

The adduct formation is due to very high intermolecular hydrogen bonding forces that was existing between urea and the carbonyl group of m-nitrobenzoic acid supported by $\mathrm{m}$ nitroaniline. Hence they were pulled towards each other to form a very strong adduct. The adduct formation is greatly influenced by the presence of methanol [7] and p-xylene [8] as solvents. 
Table 2. Assignment of FTIR data of urea adducts with m-nitrobenzoic acid - m-nitroaniline $-\mathrm{p}$ xylene mixture single crystal.

\begin{tabular}{|c|c|}
\hline Wavenumber $\left(\mathrm{cm}^{-1}\right)$ & Tentative Assignment \\
\hline 3771.17 & O-H stretching, C-H stretching - weak to medium \\
\hline 3486.89 & $\mathrm{O}-\mathrm{H}$ stretch(attached to benzene ring), broad very intense, strong \\
\hline 2930.15 & $\mathrm{C}-\mathrm{H}$ Methylene - weak to medium \\
\hline 2859.75 & $\mathrm{C}-\mathrm{H}$ Alkyl methyl - weak to medium \\
\hline 2790.17 & $\mathrm{C}-\mathrm{H}$ Aldehyde - medium \\
\hline 2600.08 & $\mathrm{C} \equiv \mathrm{N}$ (attached to benzene ring), $\mathrm{C} \equiv \mathrm{C}$ weak to medium \\
\hline 2425.06 & $\mathrm{~N}-\mathrm{H}$ (ammonium ions) multiple broad peaks \\
\hline 1930.67 & $\mathrm{C}=\mathrm{C}, \mathrm{C}=\mathrm{O}$ broad peak \\
\hline 1630.57 & $\begin{array}{l}\text { Ester Carbonyl stretch; typically sharp and intense, strong band } \\
\text { consistent with } \quad \mathrm{C}=\mathrm{C}, \mathrm{NH} \text { bend-amide II - medium }\end{array}$ \\
\hline 1521.53 & Double bond stretch, $\mathrm{N}-\mathrm{O}$ (aromatic) sharp-medium to strong \\
\hline 1472.54 & $\mathrm{C}=\mathrm{C}$ stretch, $\mathrm{C}-\mathrm{H}(\mathrm{alkyl})$ methylene- medium to strong \\
\hline 1351.06 & $\mathrm{~N}-\mathrm{O}$ (aromatic), $\mathrm{C}-\mathrm{H}$ deformation \\
\hline 1269.41 & $\mathrm{C}-\mathrm{O}$ (ethers) aromatic, carboxylic acids \\
\hline 1143.51 & C-O stretch; typically broad and intense \\
\hline 1068.77 & $\begin{array}{l}\mathrm{C}-\mathrm{O} \text { (primary alcohol) strong - broad, } \mathrm{C}-\mathrm{N} \text { (aliphatic amine) often } \\
\text { overlapped }\end{array}$ \\
\hline 890.43 & $\mathrm{C}-\mathrm{H}$ (aromatic) meta-bisubstituted benzene \\
\hline 779.10 & $\mathrm{C}-\mathrm{H}$ (aromatic) meta-bisubstituted benzene \\
\hline 711.13 & $\mathrm{C}-\mathrm{H}$ (aromatic) mono substituted benzene - strong \\
\hline
\end{tabular}

\subsection{Optical Transmission Studies}

The UV-vis-NIR study of the single crystal was done using Lambda 35 UV spectrophotometer. Figure 6 shows the optical absorption spectrum of urea adduct single crystals grown from methanol. The crystal shows good optical transmittance in the entire region; therefore this new organic adduct material is best suited for electro-optic modulation [9]. It shows a cutoff at 264.37 $\mathrm{nm}$. This reveals that, in the grown crystal the absorption is almost absent in the visible region due to its high transparency. 


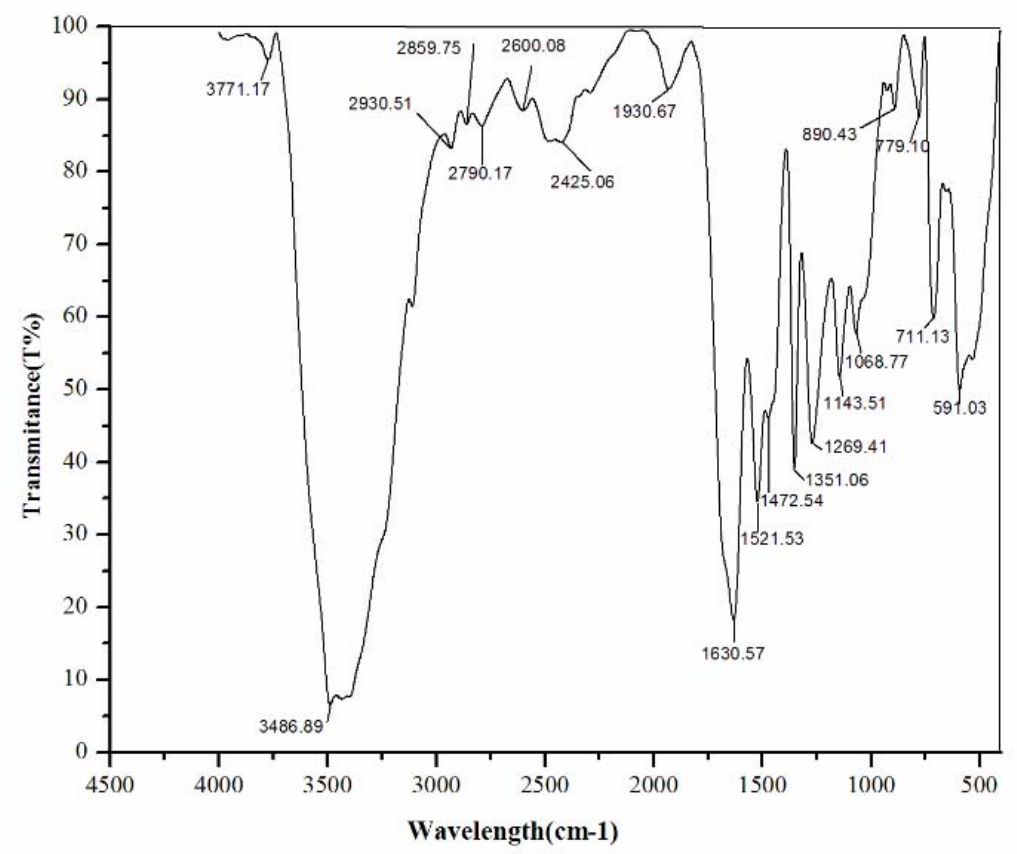

Figure 5. FTIR spectrum of urea adducts with m-nitrobenzoic acid-m-nitroanilinep-xylene mixture single crystals.

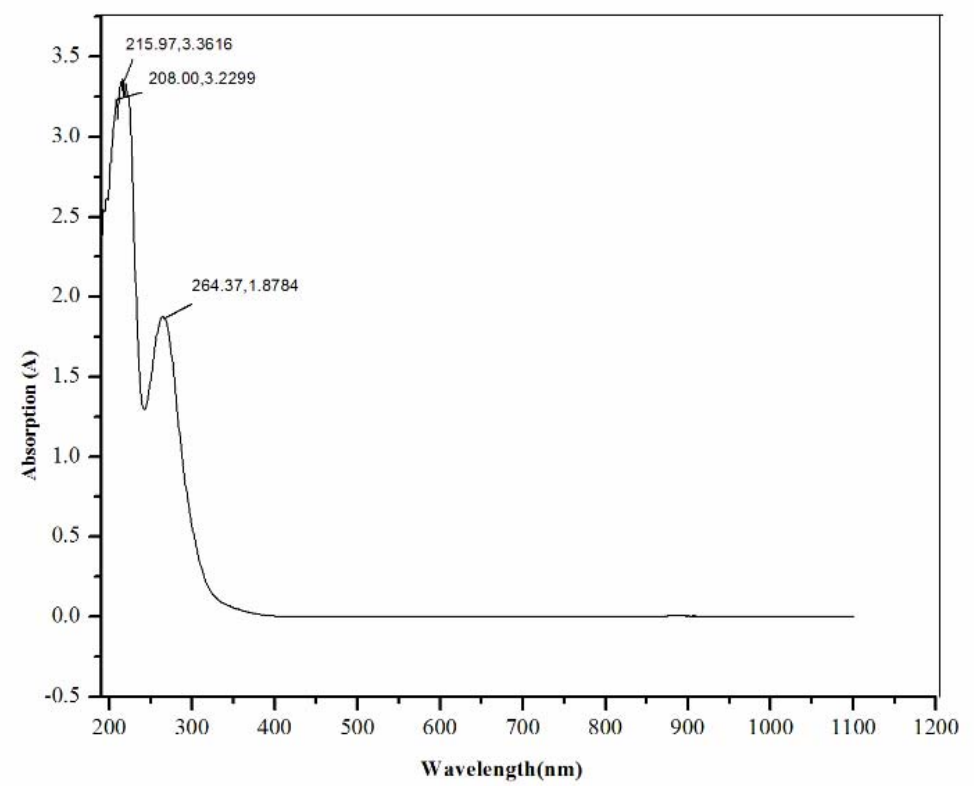

Figure 6. UV-Vis-NIR absorption spectrum of urea adducts with m-nitrobenzoic acid-mnitroaniline-p-xylene mixture single crystals. 


\subsection{Microhardness Studies}

Vicker's microhardness number was used to evaluate the anisotropy in mechanical hardness for the single crystals of thickness $3 \mathrm{~mm}$ employing a Shimadzu HMV-2 microhardness tester for different loads. The selected smooth surfaces of the crystal were subjected to Vicker's static indentation test at room temperature by applying loads ranging from 25-200 g. The Vickers hardness $\mathrm{H}_{\mathrm{V}}$ was calculated using the relation $\mathrm{H}_{\mathrm{V}}=1.8544\left(\mathrm{P} / \mathrm{d}^{2}\right) \mathrm{kg} / \mathrm{mm}^{2}$, where $\mathrm{P}$ is the applied load and $\mathrm{d}$ is the diagonal length of the indentation impression.

The microhardness value was taken as the average of the several impressions made. Crack initiation and materials chipping become significant beyond $200 \mathrm{~g}$ of the applied load. Figure 7 shows the variation of microhardness number $\left(\mathrm{H}_{\mathrm{V}}\right)$ as a function of applied load $(\mathrm{P})$.

It is clear from the figure that the microhardness number decreases with increase of load. The Mayer's number (n) is found to be 1.84, which concludes that the crystal belongs to the soft category.

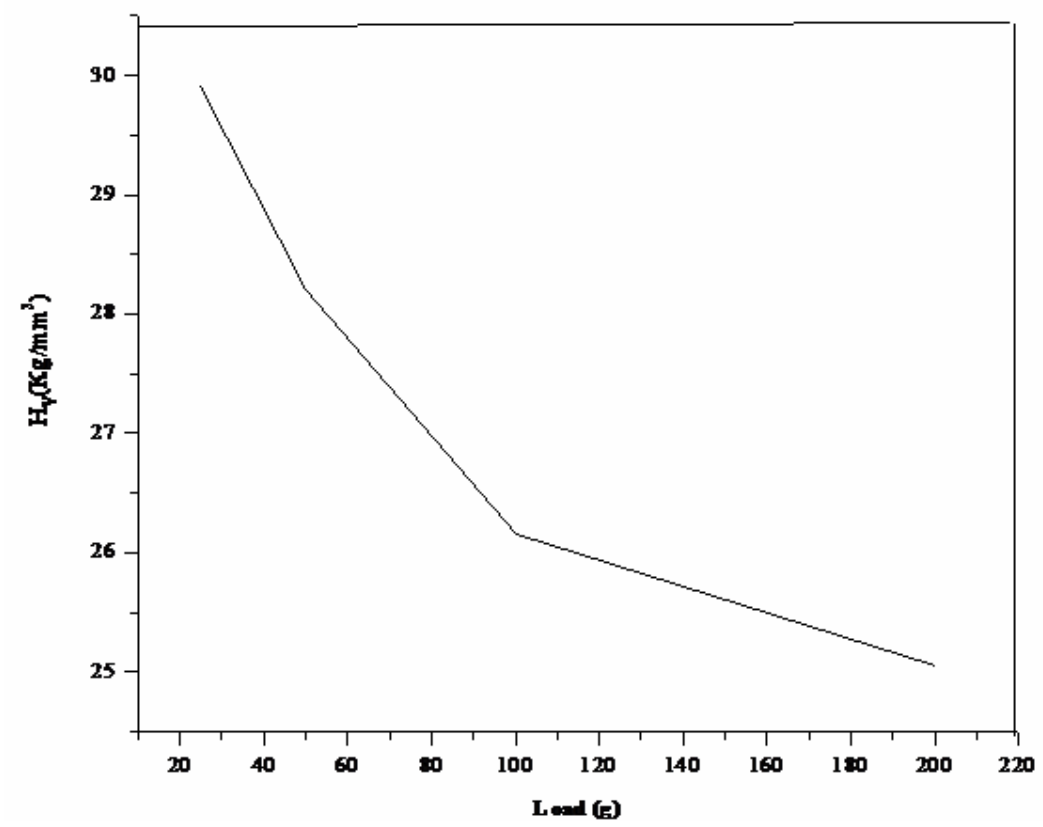

Figure 7. Variation of Microhardness number $\left(\mathrm{H}_{\mathrm{V}}\right)$ with load $(\mathrm{P})$. 


\section{CONCLUSIONS}

The urea adduct with m-nitrobenzoic acid, m-nitroaniline and $\mathrm{p}$-xylene mixture was synthesized and grown as single crystal by slow evaporation solution growth technique at room temperature. The grown crystals are nonhygroscopic and have well developed habit. The single crystal X-ray diffraction study confirmed its crystal structure belonging to monoclinic crystal system with centrosymmetric space group $\mathrm{P} 2{ }_{1} / \mathrm{c}$. The molecular packing shows four molecules per unit cell. The FTIR spectrum shows the incorporation of different functional of the guest reactants. The adduct formation of urea with its guests in a very strong manner is highly influenced by $p$-xylene and methanol. The strong forces provided by the secondary bonding between the amide and carboxyl group has favored the electron transfer between them. The excellent transparency in the entire UV-vis-NIR region facilitates this material to various optical applications. The microhardness studies concludes the category of the organic adduct crystal as soft category.

\section{ACKNOWLEDGEMENT}

This work, supported by the Department of Science and Technology, New Delhi, India under the grant of project ref- SR/FTP/PS-20/2005, is hereby gratefully acknowledged. One of the authors (P. Jagdish) thanks Sona College of Technology, Salem, India for their help and encouragement to carry out this research work.

\section{REFERENCES}

[1] David P. Shoemaker, Jerry Donohuem, Verner Schomaker, Robert B. Corey, 1950, "The Crystal Structure of $\mathrm{L}_{\mathrm{s}}$-Threonine.” J. Am. Chem. Soc. Vol. 72(6), pp. 2328-2349.

[2] D.S. Chemla and J. Zyss, 1987, Nonlinear optical properties of organic molecules and crystals, Academic Press.

[3] R.T. Denton, F.S. Chen, A.A. Ballman, 1967, "Lithium Tantalate Light Modulators" J. Appl. Phys. Vol. 38, pp. 1611-1617.

[4] M. Ebrahimzadeh, M.H. Dunn, F. Akerboom, 1989, "Highly efficient visible urea optical parametric oscillator pumped by XeCl excimer laser" Optical Lett. Vol. 14, pp. 560-562.

[5] D.J. Halfpenny, J.N. Sherwood, 1990, "Synchrotron-radiation section topography of large uncut crystals of organic nonlinear optical materials." Philos. Msg. Lett. Vol. 62, pp. 1-7.

[6] Joseph Zyss, 1982, "New organic molecular materials for nonlinear optics," J. Non. Crystalline Solids, Vol. 47, pp. 211-225.

[7] A.A. Gundyrev, L.P. Kazakova, M.V. Karaibog, 1977, "Influence of alcohols on ureaadduct formation with solid paraffins." Chem. And Tech. of Fuels and Oils, Vol. 13, pp. 101104. 
[8] Alfred Fischer, John Neilson Ramsay, 1974, "Formation of Adducts in the Nitration of pXylene. Exchange and Rearomatization of p-Xylene Adducts." Can. J. Chem. Vol. 52, pp. 3960-3970.

[9] A. S. Haja Hameed, G. Ravi, A. Nixon Azariah, T. Mahalingam, P. Ramasamy, 2003, "Growth and optical characterization of organic nonlinear optical crystal: indole-3Aldehyde." Phys. Chem. Sol. Vol. 64, pp. 147-153. 